\title{
The Biological Synthesis of Silver Nanoparticles by Mango Plant Extract and Its Anti-Candida Effects
}

\author{
Shadi Salati ${ }^{1}$, Monir Doudi ${ }^{*}$, Mahboobe Madani ${ }^{2}$ \\ ${ }^{1}$ Department of Microbiology, Falavarjan Branch, Islamic Azad University, Falavarjan, Isfahan, Iran \\ ${ }^{2}$ Department of Microbiology, Falavarjan Branch, Islamic Azad University, Isfahan, Iran
}

Corresponding Author: Monir Doudi, PhD, Assistant Professor, Department of Microbiology, Falavarjan Branch, Islamic Azad University, Isfahan, Iran. Tel: 098-3137420143,Email: Dodi_m@iaufala.ac.ir

Received June 15, 2018; Accepted November 2, 2018; Online Published December 20, 2018

\begin{abstract}
Introduction: In recent years, using plant products alone and along with metal nanoparticles has been widely considered in preventing or killing pathogens including fungi. Increasing the use of chemical drugs has increased the resistance of pathogenic fungi. The present study aimed at investigating the biological synthesis of silver nanoparticles by mango plant extract and its anti-Candida effects.

Materials and Methods: First, the Indian mangoes were bought from the Isfahan fruit and vegetable market and the kernel were extracted. Then, the nanoparticles synthesis was conducted on mango cores and the synthesized nanoparticles were evaluated using a UV-VIS, X-ray diffraction (XRD) machine and a transient electron microscope. In this study, the anti-Candida effects of mango core nanoparticles was evaluated on 21 clinical isolates and 3 standard strains of Candida including Candida albicans PPTCC 5027, Candida glabrata PTCC 5297 and Candida krusei PTCC 5295 using a quantitative micro dilution method (serial dilution in tubes). For data analysis, ANOVA test and SPSS version 22 software were used at the significance level of $P \leq 0.05$. Duncan test was also used to analyze the groups.

Results: Based on the results, the synthesized nanoparticles were cubic and $65 \mathrm{~nm}$ in size. Among the clinical isolates, C. albicans with the frequency of $52.38 \%$ and C. glabrata with the frequency of $4.76 \%$ had the highest and lowest frequency among the 21 clinical isolates. C. glabrata had the most sensitivity with the quantitative serial dilution method (microdilution) with minimum inhibitory concentration (MIC) of fungal growth $(0.016 \mathrm{mg} / \mathrm{mL})$ and the minimum lethal concentration of fungi $(0.032 \mathrm{mg} / \mathrm{mL})$ against the nanoparticles of mango core $(P \leq 0.001)$.

Conclusions: The inhibitory effect of the mango core nanoparticles after fluconazole on the majority of clinical and standard strains of Candida had a direct relationship with the increasing concentrations of this substance. However, further studies are required for determining the effect of this bio-nanoparticle on the treatment of Candida infections in human beings.

Keywords: Mango Core Extracts, Anti-Candida Effect, XRD, TEM, UV-VIS Microdilution

Citation: Salati S, Doudi M, Madani M. The biological synthesis of silver nanoparticles by mango plant extract and its anti-Candida effects. J Appl Biotechnol Rep. 2018;5(4):157-161. doi:10.29252/JABR.05.04.04.
\end{abstract}

\section{Introduction}

Among the main causes of infectious diseases with Candida fungal infections are a very important model of human pathogens. Candida albicans is a dwarf fungus and an important component of the natural flora of healthy people. In a situation where the immune system is weakened, Candida, as an opportunistic pathogen, can develop diseases after transferring from the symbiotic phase to the pathogenic phase. Different species of this yeast are able to form biofilms and are the leading cause of mortality in immunocompromised patients. Since they cause invasive candidiasis, it is difficult to eradicate them using antifungal therapy. In fighting against the fungal infections, 3 main flaws can be considered for some antifungal drugs: first, they operate in a limited range, second they can negatively react with different types of antifungal agents, and third they can make the microorganisms resistant. In addition, despite the advances in the treatment of fungal infections using antifungal compounds over the past thirty years, the antifungal resistance is still a major concern in clinical practice. In general, the advancement in the production of new antibiotics involves long and costly processes that can now be solved with the development of nanoscience science. ${ }^{1}$

Nano-biotechnology has been making progress in recent decades and will have widespread effects on various aspects of human life including pharmacy and medicine in the near future. Nowadays, the growing need for reliable methods for making nanoparticles which do not harm the environment has made the researchers extremely interested in this field. Many organisms, whether monocellular or multicellular, are known to produce inorganic nanoparticles acting as intracellular or extracellular. Plant extracts are among the biological systems which have been recently considered in this field. Mango is one of the most popular tropical fruits in most parts of the world which is cultivated abundantly in South Asian countries. Mangoes belong to the Mangifera

Copyright $\odot 2018$ The Author(s). This is an open-access article distributed under the terms of the Creative Commons Attribution License (http:// creativecommons.org/licenses/by/4.0), which permits unrestricted use, distribution, and reproduction in any medium, provided the original work is properly cited. 
species from the Anacardiaceae family. Mangifera contains several species of edible fruit. The tree of fruits we know as mango belongs to the Mangifera indica species. Nowadays, the mango is considered to be one of the 3 or 4 optimal fruits of tropical regions. Its origin is northeastern India, northern Burma and probably Silane. Mango core contains active bioactive compounds with high antioxidant activity. ${ }^{2}$ Mango has anti-viral and antibacterial properties, due to the presence of compounds such as phenolic compounds. ${ }^{3}$ Ethanol extract of mango kernel has a good antimicrobial activity against a variety of pathogenic bacteria such as Escherichia coli, Pseudomonas aeruginosa, Staphylococcus aureus, Streptococcus pyogenes, and Klebsiella pneumoniae. ${ }^{4}$

Ethyl acetate and ethanol derived from mango peel extract showed strong antifungal activity against pathogenic fungi such as Rhizoctonia solani. ${ }^{5}$ Given that nanobiotechnology is seeking to discover the substances that are more specialized and effective in treating various diseases, including fungal diseases and based on the antimicrobial properties of green nanoparticles and the lack of precise knowledge of the specific effects of Candida species, it is necessary to conduct precise tests for studying the effects of these compounds on the above-mentioned yeast. The mango core contains bioactive compounds with high antioxidant activity. Researchers have shown that the ethanolic extract of mango core has antimicrobial activity against pathogenic bacteria such as $E$. coli, P. aeruginosa, S. aureus, S. pyogenes, and K. pneumoniae. ${ }^{5}$

\section{Materials and Methods}

In this study, first the standard strains of C. albicans PTCC 5027and C. glabrata PTCC 5297 and Candida krusei PTCC 5295 were purchased from the Tehran Research Institute of Technology. Clinical isolates were comprised of 16 isolates from Shafa Laboratory, Isfahan, 3 isolates from Mahdieh Laboratory, and 2 isolates from Shahid Beheshti Hospital in Isfahan. All clinical isolates were identified by direct lam, Germ tube formation, clamidoconidia production in corn meal agar medium, and culture CHROMagar medium. In order to prepare the nanoparticles of mango kernel, first the mango core was removed from 2 lignin and cellulose shells. Then, they were washed several times with sterilized distilled water and crushed and autoclaved into ultra-small pieces by a meat grinder. After on, the pieces were dried in an oven at $250^{\circ} \mathrm{C}$ for 2 hours. In the next step, $500 \mathrm{~g}$ of powder was dried. The mango kernels were extracted with $50 \%$ cc of alcohol within the Soxhlet tank and then the extracts were passed through Whatman filter papers grade 4 .

In order to synthesize the nanoparticles of mango kernels, first $1.69 \mathrm{~g}$ of silver nitrate powder was mixed with $100 \mathrm{~mL}$ sterile distilled water. Then, $2 \mathrm{~g}$ of mango extract powder were added to the above substance and were then placed in oven at $60^{\circ} \mathrm{C}$ for 30 minutes. The device was turned off after reaching the boiling point $\left(100^{\circ} \mathrm{C}\right)$. In the next step, the solution was biphasic and some crystals appeared on the solution. Then, the supernatant was washed several times with sterilized deionized water to wash the excess salts and the obtained sediments were dried by using an oven at $37^{\circ} \mathrm{C}$ for $42-72$ hours. ${ }^{6}$ For the final use, the dried powder obtained from the previous stage was re-exposed at $60^{\circ} \mathrm{C}$ for 48 hours and the samples were completely dried. After analyzing qualitative changes in the black color of the prepared samples, an amount of the resulting liquid was isolated to evaluate the absorption spectrum using a UV-VIS spectrophotometer. Then, the samples were sent to the Faculty of Materials Science, Isfahan University of Technology, to determine the morphological and physicochemical properties of the samples analyzed by the X-ray diffraction (XRD) device.

The samples were then sent to the Ferdowsi University of Mashhad's laboratory for the microscopic identification of the samples synthesized by the TEM device. In order to determine the sensitivity of yeasts to the nanoparticles of mango kernels, the micro dilution method was used. For this purpose, the serial dilution of $0.002,0.004,0.008,0.016$ and $0.032 \mathrm{mg} / \mathrm{mL}$ from mango bio-nanoparticles was prepared in the injectable distilled water solvent. With the help of this method, the minimum inhibitory concentration (MIC) and minimum fungal concentration (MFC) were determined. Fluconazole was used as a positive control and the physiologic serum was used as a negative control. ${ }^{7}$

In order to compare the mean diameter of non-growth yeast halves for each patient between different groups, oneway ANOVA test was used by SPSS software version 22 . Moreover, Duncan test was used to examine the significant difference between different groups.

\section{Results}

The Results of XRD Diagram for Mango Core Nanoparticles The results obtained from Figure 1, illustrated by the XRD device, showed the peaks at 111, 200, and 220 levels being consistent with silver nano-crystal reference cards (JCDD040789). Figure 1 shows the scheme obtained from an XRD device for silver nanoparticles with mango core produced at $60^{\circ} \mathrm{C}$.

The Results of UV-VIS Diagram for Mango Core Nanoparticles A UV-VIS absorption spectrum of the mango core nanoparticles has been presented in Figure 2, in the presence of $1 \mathrm{mM}$ silver nitrate at $500^{\circ} \mathrm{C}$. As it is clear, it has a peak at $345 \mathrm{~nm}$.

The Results of TEM Images for Mango Core Nanoparticles The analysis results of TEM images showed the production of nanoparticles produced by mango core extract in a size of 65

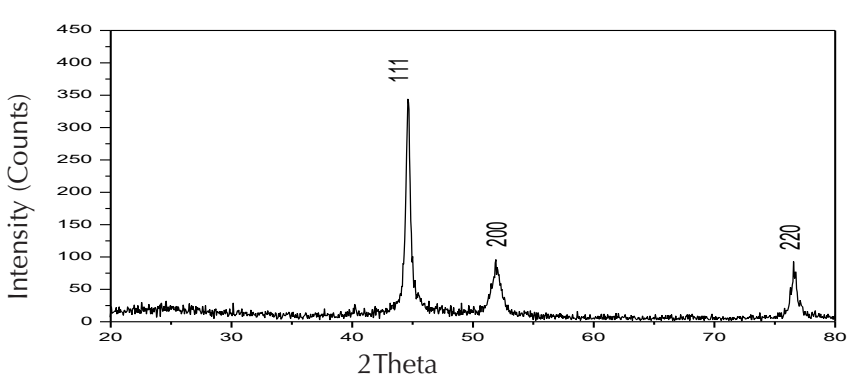

Figure 1. The Scheme Obtained From the X-Ray Diffraction Device of Mango Core Nanoparticles. 


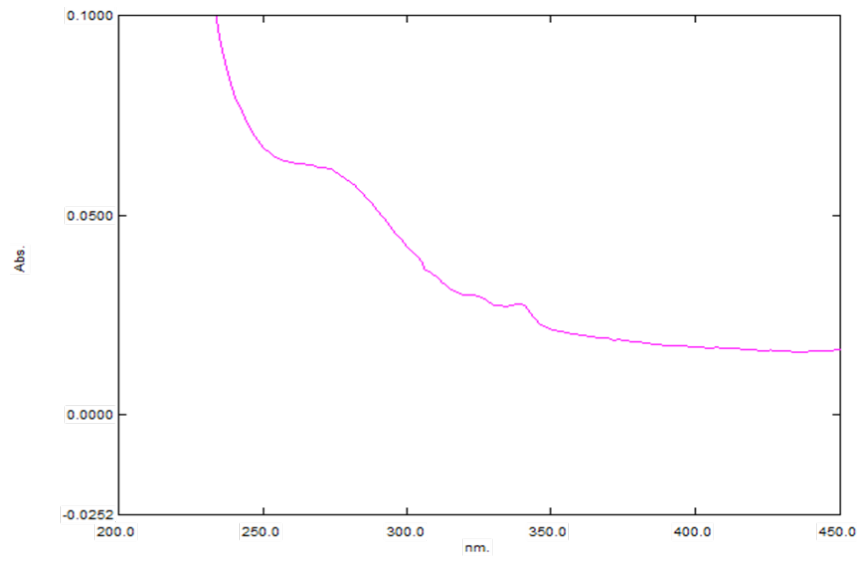

Figure 2. The UV-VIS Absorption Spectrum of Mango Core Nanoparticles.

$\mathrm{nm}$. Figure 3 shows the image prepared from the transmission electron microscope (TEM).

\section{The Results of Isolates Collection}

This study was conducted on 21 samples sent by several laboratories in Isfahan.

After the initial screening, 11 isolates of C. albicans, 7 isolates of C. krusei, 2 isolates of Candida tropicalis and 1 isolate of C. glabrata were among the isolates. The results of identifying these isolates are presented in Table 1.

Table 2 shows the MIC of fungi and also the MFC concentration in $\mathrm{mg} / \mathrm{mL}$ against the various concentrations of mango core nanoparticles.

\section{Discussion}

The importance of opportunistic fungal diseases in patients with immune deficiency (diabetics, cancers, transplants, and certain diseases) and especially cellular immunity is not hidden to anyone. Candidiasis is undoubtedly one of the most prevalent opportunistic fungal diseases in humans which is acute and chronic in the skin, nail, mucosa, vagina, lung and gastrointestinal tract or is observed systemically with blood poisoning, endocarditis, and meningitis. ${ }^{8}$ The main problems in the treatment of patients with fungal infections, especially Candida, is resistance to antifungal agents, as well as an increased incidence of fungal infections or their recurrence, and also the use of different antifungal medicines. ${ }^{9}$ In addition, the infections associated with C. albicans, C. glabrata, and C. krusei are often treated with difficulty and most of the strains are less susceptible to antifungal drugs. Thus, it is necessary to adopt new therapies which are not only effective

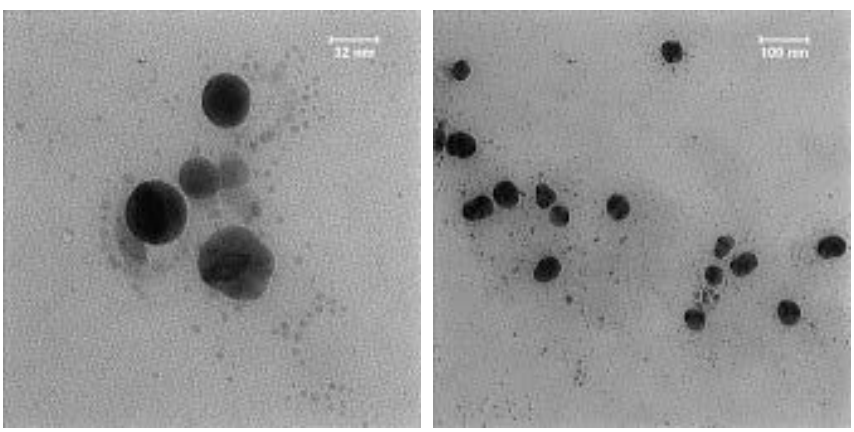

Figure 3. The Image Prepared From Mango Core Nanoparticles Using the TEM Microscope

on these resistant strains, but also have no harmful or toxic effects for animal or human consumptions. ${ }^{10}$ Nowadays, many researchers investigate the antifungal effects of metallic nanoparticles alone or in combination with plant extracts which may be attributed to the different physico-chemical properties of these substances and antibacterial, antiviral, and anti-parasitic effects of these nanoparticles. ${ }^{11}$ The XRD analysis was performed to prove the nanocrystals of mango core. Based on the findings of Figure 1, the nanocrystals of mango core were consistent with silver nanocrystal reference card (JCDD04-0783) on 111, 200, 220 levels at $60^{\circ} \mathrm{C} .{ }^{12}$ In this project, the results of the UV-VIS graph had a specific absorption peak at $345 \mathrm{~nm}$, and also showed a peak at $278 \mathrm{~nm}$. The results of analyzing the TEM images according to Figure 3 indicated the production of mango core nanoparticles in spherical cubic and the size of $65 \mathrm{~nm}$. Based on the findings, the changes created in the type of production, diameter, shape, and concentration of different nanoparticles have led to different results in the antifungal activity of these particles. ${ }^{13,14}$

Kim et al reported that the antifungal activity of silver nanoparticles in spherical shape against pathogenic fungi such as Trichophyton mentagrophytes and Trichosporon beigelii had a greater effect than the current antifungal agents such as fluconazole and amphotripsin B. ${ }^{15}$ Based on Table 2 indicating the MIC and MFC results of mango core nanoparticles and Fluconazole standard and clinical samples of Candida by microdilution method, the highest MIC belonged to C. albicans 2, 5 and 9, C. krusei 1 and 2, and $C$. tropicalis 1 affected by $0.032 \mathrm{mg} / \mathrm{mL}$ concentration of mango kernel nanoparticles. However, the highest MFCs of these isolates was $0.064 \mathrm{mg} / \mathrm{mL} .{ }^{15}$ The results of Bahrami Abdehgah et al showed that the highest MIC for C. glabrata belonged to copper and silver nanoparticles each with a concentration of about $31 \mathrm{ppm}$ and MFC of $62.5 \mathrm{ppm} .{ }^{16}$ However, in the

Table 1. The Results of Identification Tests on Different Candida Species

\begin{tabular}{|c|c|c|c|c|}
\hline $\begin{array}{l}\text { Name of Species, type of } \\
\text { Yeast, and Percentage of } \\
\text { Frequency }\end{array}$ & $\begin{array}{l}\text { Direct Smear } \\
\quad \text { Results }\end{array}$ & Germ Tube Production & Clamydoconidia Production & $\begin{array}{c}\text { Color of Yeast Colony on Chromagar } \\
\text { Medium }\end{array}$ \\
\hline Candida albicans, 52.38\% & Round yeast cells & + & + & Light green \\
\hline Candida glabrata, $4.76 \%$ & Elliptic yeast cells & - & - & Dark violet with pink margins \\
\hline Candida krusei, 33.33\% & Yeast cells & - & - & - \\
\hline Candida tropicalis, $9.52 \%$ & Yeast cells & - & - & Blue or gray purple \\
\hline
\end{tabular}


Table 2. MIC and MFC Rates in mg/mL for Nanoparticles of Mango Core and Fluconazole on Standard and Clinical Candidates of Candida

\begin{tabular}{|c|c|c|c|c|}
\hline $\begin{array}{l}\text { Genus and Species of } \\
\text { Candida }\end{array}$ & $\begin{array}{c}\text { MIC Mango Core } \\
\text { Nanoparticles }(\mathrm{mg} / \mathrm{mL}) \\
\end{array}$ & $\begin{array}{c}\text { MIC Fluconazole (mg/ } \\
\mathrm{mL})\end{array}$ & $\begin{array}{l}\text { MFC Mango Kernel Core } \\
\text { Nanoparticles (mg/mL) }\end{array}$ & $\begin{array}{c}\text { MFC Fluconazole } \\
(\mathrm{mg} / \mathrm{mL})\end{array}$ \\
\hline C. albicans 1 & 0.008 & 0.008 & 0.016 & 0.016 \\
\hline C. krusei 1 & 0.032 & 0.002 & 0.064 & 0.004 \\
\hline C. albicans 2 & 0.032 & 0.032 & 0.064 & 0.064 \\
\hline C. albicans 3 & 0.080 & 0.032 & 0.016 & 0.064 \\
\hline C. tropicallis 1 & 0.032 & 0.003 & 0.064 & 0.004 \\
\hline C. glabrata 1 & 0.016 & 0.004 & 0.032 & 0.008 \\
\hline C. krusei 2 & 0.032 & 0.002 & 0.064 & 0.004 \\
\hline C. albicans 4 & 0.008 & 0.016 & 0.014 & 0.032 \\
\hline C. albicans 5 & 0.032 & 0.008 & 0.064 & 0.016 \\
\hline C. krusei 3 & 0.016 & 0.004 & 0.034 & 0.008 \\
\hline C. krusei 4 & 0.016 & 0.002 & 0.032 & 0.004 \\
\hline C. krusei 5 & 0.008 & 0.002 & 0.016 & 0.004 \\
\hline C. albicans 6 & 0.016 & 0.008 & 0.032 & 0.016 \\
\hline C. albicans 7 & 0.016 & 0.002 & 0.032 & 0.004 \\
\hline C. albicans 8 & 0.016 & 0.002 & 0.032 & 0.004 \\
\hline C. albicans 9 & 0.008 & 0.002 & 0.016 & 0.004 \\
\hline C. tropicalis 2 & 0.016 & 0.004 & 0.032 & 0.008 \\
\hline C. krusei 6 & 0.008 & 0.008 & 0.016 & 0.016 \\
\hline C. albicans 10 & 0.016 & 0.002 & 0.032 & 0.008 \\
\hline C. krusei 7 & 0.016 & 0.008 & 0.032 & 0.016 \\
\hline C. albicans 11 & 0.016 & 0.008 & 0.032 & 0.016 \\
\hline C. albicans 5027 & 0.016 & 0.002 & 0.032 & 0.004 \\
\hline C. glabrata 5297 & 0.002 & 0.004 & 0.004 & 0.008 \\
\hline C. glabrata 5295 & 0.016 & 0.004 & 0.032 & 0.008 \\
\hline
\end{tabular}

same study, the lowest MIC for silver nanoparticles with amphotericin B was reported to be 8 ppm and MFC equivalent to $15.5 \mathrm{ppm}$. The results of this study are partly consistent with the present study where the lowest amount of MIC in standard C. glabrata 5297 was $0.002 \mathrm{mg} / \mathrm{mL}$ against silver nanoparticles along with mango kernel. In addition, its MFC level was reported to be $0.04 \mathrm{mg} / \mathrm{mL}$.

In the present study, the effect of mango core nanoparticles had more appropriate antifungal property against C. glabrata than fluconazole. These findings are in line with the results of a study by Nafisa et al. which had been conducted on fungal pathogens of C. albicans, C. glabrata, and C. tropicalis. ${ }^{17}$ Furthermore, in another study, Asghari et al investigated the antifungal effects of silver nanoparticles on Candida vulvovaginal factors in vitro. The results of this study showed that silver spherical nanoparticles with a diameter of $10 \mathrm{~nm}$ had antifungal activity against C. albicans to some degree. The MIC amount of the isolates was reported 25.31 to ppm and the MFC of the samples was 62.5 to 250 ppm. ${ }^{18}$ In 2016 Valenti et al evaluated the activity of two antifungal drugs (amphotericin B and voriconazole) simultaneously against 5 different candida species that were able to create biofilm. The reported MIC rate of this compound was $0.004 \mathrm{mg} / \mathrm{mL}$ and MFC was $0.008 \mathrm{mg} / \mathrm{mL}$, which is comparable to some candida species in the present study. ${ }^{19}$

\section{Conclusions}

The findings of this study revealed that the nanoparticles of the mango core had the most anti-candida property on the clinical strain of C. glabrata by the micro dilution method as well as on the standard strain of this yeast, C. glabrata 5297 which could be compared to the antifungal agent of fluconazole. However, the effect of flokonazole was more than the cubic mango core nanoparticles with a diameter of $65 \mathrm{~nm}$ in case of C. albicans, C. krusei, and C. tropicallis.

\section{Authors' Contributions}

SS and MD contributed to design of the project and performed the laboratory data collection and data analysis. MM helped to design of the project and data analysis.

\section{Conflict of Interest Disclosures}

The authors declare they have no conflicts of interest.

\section{Acknowledgments}

The authors would like to appreciate the authorities of the research laboratory of the Islamic Azad University of Falavarjan, especially Ms. Shahsar. In addition, the authors of this study would like to thank the authorities of the Taligene Pars knowledge enterprise located in the Isfahan scientific-research town for their very helpful cooperation and guidance.

\section{References}

1. Vazquez-Munoz R, Avalos-Borja M, Castro-Longoria E. Ultrastructural analysis of Candida albicans when exposed to silver nanoparticles. PLoS One. 2014;9(10):e108876. doi:10.1371/ journal.pone.0108876.

2. Torres-Leon C, Rojas R, Contreras-Esquivel JC, Serna-Cock L, Belmares-Cerda RE, Aguilar CN. Mango seed: Functional and nutritional properties. Trends Food Sci Technol. 2016;55:109-117. doi:10.1016/j.tifs.2016.06.009.

3. Ribeiro S, Schieber A. Bioactive compounds in mango (Mangifera 
indica L.). Bioactive Foods in Promoting Health; 2010:523-507. doi:10.1016/b978-0-12-374628-3.00034-7.

4. Ahmed EF. Antimicrobial and antibiofilm activity of mango seeds extract. Iraq J Sci. 2015;56(4B):3121-3129.

5. Qin LJ, Wang Q, Wu LY. Stability of antimicrobial activities of mango (Mangifera indica L.) peel extracts. Guangxi Agric Sci. 2007;4:423-426.

6. Agasti N, Kaushik NK. One pot synthesis of crystalline silver nanoparticles. Am J Nanomater. 2014;2(1):4-7. doi:10.12691/ajn2-1-2.

7. Santhoshkumar T, Rahuman AA, Rajakumar G, et al. Synthesis of silver nanoparticles using Nelumbo nucifera leaf extract and its larvicidal activity against malaria and filariasis vectors. Parasitol Res. 2011;108(3):693-702. doi:10.1007/s00436-010-2115-4.

8. Kateiraei F, Khosravi A, Khalaj V, Haji Abdolbaghi M. Sensitivity of oral candidates for HIV-infected personal to antifungal ducts under exogenous conditions in Iran. Journal of Faculty of Medicine, Tehran University of Medial Sciences. 2012;70(2):96163. [Persian].

9. Dadar M, Tiwari R, Karthik K, Chakraborty S, Shahali Y, Dhama K. Candida albicans - Biology, molecular characterization, pathogenicity, and advances in diagnosis and control - An update. Microb Pathog. 2018;117:128-138. doi:10.1016/j. micpath.2018.02.028.

10. Silver S. Bacterial silver resistance: molecular biology and uses and misuses of silver compounds. FEMS Microbiol Rev. 2003;27(23):341-353. doi:10.1016/s0168-6445(03)00047-0.

11. Schultz S, Smith DR, Mock JJ, Schultz DA. Single-target molecule detection with nonbleaching multicolor optical immunolabels. Proc Natl Acad Sci U S A. 2000;97(3):996-1001.
12. Park HH, Zhang $X$, Choi YJ, Park HH, Hill RH. Synthesis of $\mathrm{Ag}$ nanostructures by photochemical reduction using citrate-capped Pt seeds. J Nanomater. 2011;2011:265287. doi:10.1155/2011/265287.

13. Kim KJ, Sung WS, Suh BK, et al. Antifungal activity and mode of action of silver nano-particles on Candida albicans. Biometals. 2009;22(2):235-242. doi:10.1007/s10534-008-9159-2.

14. Falkiewicz-Dulik M, Macura AB. Nanosilver as substance biostabilising footwear materials in the foot mycosis prophylaxis. Med Mycol. 2008;15(3):145-150.

15. Kim KJ, Sung WS, Moon SK, Choi JS, Kim JG, Lee DG. Antifungal effect of silver nanoparticles on dermatophytes. J Microbiol Biotechnol. 2008;18(8):1482-1484.

16. Bahrami Abdehgah I, Khodavandi A, Shamsazar A, Negahdary $M$, Jafarzadeh $M$, Rahimi $G$. In vitro antifungal effects of biosynthesized silver nanoparticle by Candida albicans against Candida glabrata. Biomed Res. 2017;28(7):2870-2876.

17. Khatoon N, Mishra A, Alam H, Manzoor N, Sardar M. Biosynthesis, characterization, and antifungal activity of the silver nanoparticles against pathogenic Candida species. BioNanoScience. 2015;5(2):65-74. doi:10.1007/s12668-015-0163-z.

18. Asghari A, Rakhsh N, Madani M. Antifungal effect of silver nanoparticles on candidate factors of vulvovaginitis in laboratory conditions. Iran J Microbiol. 2015;9(3):23-29.

19. Valentin A, Canton E, Peman J, Fernandez-Rivero ME, Tormo-Mas MA, Martinez JP. In vitro activity of anidulafungin in combination with amphotericin B or voriconazole against biofilms of five Candida species. J Antimicrob Chemother. 2016;71(12):34493452. doi:10.1093/jac/dkw316. 